Disclosures Susana Banerjee has received institution research grants from AstraZeneca, Tesaro, and GlaxoSmithKline, and honoraria for advisory boards/lectures from AstraZeneca, Amgen, Clovis, Genmab, GlaxoSmithKline, Immunogen, Mersana, Merck Serono, Merck Sharp \& Dohme, Pfizer, Roche, Seattle Genetics, and Tesaro.

Ana Oaknin has served on advisory boards for Clovis Oncology, AstraZeneca, Genmab/Seattle Genetics, ImmunoGen, PharmaMar, Roche, GSK/Tesaro, Merck/Merck Sharp \& Dohme, Deciphera and Mersana; has received support for travel or accommodation from Clovis Oncology, AstraZeneca, PharmaMar, and Roche; and reports institutional research grant support from Clovis Oncology, AbbVie Deutschland, Ability Pharmaceuticals, Advaxis, Aeterna Zentaris, Amgen, Aprea Therapeutics, Eisai, ImmunoGen, Merck/Merck Sharp \& Dohme, Millennium Pharmaceuticals, PharmaMar, Roche, and Tesaro.

IS-S: No conflicts to disclose

ACS: No conflicts to disclose

Sandip Pravin Patel receives scientific advisory income from AstraZeneca, Bristol Myers Squibb, Eli Lilly, Illumina, Rakuten, Paradigm and Tempus, and research funding from Bristol Myers Squibb, Eli Lilly, Incyte, AstraZeneca, Merck, Pfizer, Roche/Genentech, Xcovery, Fate Therapeutics, Genocea and Iovance.

AOz: No conflicts to disclose

Mayukh Das is an employee of and stockholder in AstraZeneca.

Panagiotis Kourtesis is an employee of and stockholder in AstraZeneca.

Maria Libera Ascierto is an employee of and stockholder in AstraZeneca.

Jennifer R. Diamond reports research funding from AstraZeneca, Immunomedics, OnKure, Bristol Myers Squibb, Merck, Deciphera, Bayer, Taiho and Takeda and consulting work for Immunomedics.

\section{SOX2 EXPRESSION IN OVARIAN SEROUS EPITHELIAL CANCER}

${ }^{1}$ Irena Conic, ${ }^{2}$ Slavica Stojnev, ${ }^{2}$ Ljubinka Jankovic Velickovic, ${ }^{2}$ Biljana Djordjevic, ${ }^{1}$ Aleksandra Dimitrijevic, ${ }^{2}$ Krstic Miljan, ${ }^{2}$ Ana Ristic Petrovic, ${ }^{2}$ Ivana Djordjevic, ${ }^{1}$ Dane Krtinic. ${ }^{1}$ Clinic of Oncology, Clinical Center Nis, Serbia; University of Nis, Faculty of Medicine, Nis, Serbia; ${ }^{2}$ Center for Pathology, Clinical Center Nis, Nis, Serbia; University of Nis, Faculty of Medicine, Nis, Serbia

\subsection{6/ijgc-2020-ESGO.148}

Introduction/Background The transcription factor Sox2 is highly expressed in embryonic stem cells and is considered to act as a key driver of stem-like properties of cancer cells.

Methodology This study aimed to investigate the immunohistochemical expression profile of Sox 2 in ovarian serous epithelial cancer, to determine its potential significance in disease prognosis, association with clinical and pathological parameters, as well as with patient survival.

Results A total of 270 patients were enrolled in the study. In FIGO stage I tumors Sox2 expression was absent in $28.9 \%$ of the tumors, while high Sox 2 expression was significantly less frequent $(7.0 \%, \mathrm{p}<0.01)$. Significantly higher Sox2 expression compared with low expression was found in the third FIGO stage $(65 \%$ vs.43.2\%; p <0.01). Disease progression was recorded in $23.1 \%$ of patients with high Sox 2 expression, which is significantly higher in comparison to patients without
Sox2 expression (11.4\%; p <0.05). Partial remission was observed in $14.1 \%$ with high Sox 2 expression and this was significantly lower than in subjects with low Sox2 expression $(28.8 \%$; p <0.05) or without Sox2 expression (34.3\%; p $<0.01)$. Overall survival was the longest in the group without Sox2 expression, while the mortality was more prevalent in the group with high expression, but without statistical significance.

Conclusion The study showed that Sox 2 overexpression in ovarian serous epithelial cancer was associated with the unfavorable clinical course of the disease.

Disclosures No

\section{FERTILITY AND PREGNANCY OUTCOMES AFTER FERTILITY-SPARING TREATMENT IN OVARIAN CANCER PATIENTS}

Flavia Sorbi, Emanuele Arturo Fera, Roberto Domenico Cincotta, Fambrini Massimiliano, Irene Ladisa, Chiara Biagiotti, Francesca De Bonis, Rachele Gaddi, Maria Elisabetta Coccia. Department of Biomedical, Experimental and Clinical Sciences, Division of Obstetrics and Gynecology, University of Florence, Florence, Italy

\subsection{6/ijgc-2020-ESGO.149}

Introduction/Background Incidence of ovarian cancer (OC) among reproductive-aged women has increased. Unlike cervical cancer, there are scanty recomandations on fertility-sparing treatment for OC.

The aim of this study is to evaluate fertility and obstetrics outcomes in patients with history of OC after fertility-sparing surgical treatment.

Methodology A prospective single-center study was performed on patients with stage I OC diagnosis made between January 2013 and December 2016 at the Careggi University Hospital in Florence. Data were collected with a telephone questionnaire in order to analyzed not only oncological outcomes but also fertility and pregnancy outcomes.

Results A total of sixteen patients with OC were enrolled. The average age of patients at diagnosis was 29 years, and twelve patients were nulliparous. Most of them (11 pts, $68,75 \%$ ) had serous low-grade OC (LGOC), 12,5\% high grade serous OC, $12,5 \%$ juvenile granulosa cell cáncer and one patient $(6,25 \%)$ had mucinous LGCOS. There patients $(18,5 \%)$ underwent adjuvant chemotherapy as their stage was IC. Mean follow-up was 63 months, OS rate was $100 \%$, PFS at three year was $72,5 \%$. Pregnancy outcomes were better among those patients who underwent ART $(n=10)$, with $100 \%$ of pregnancy rate vs $75 \%$ the other six patients $(\mathrm{p}<$ $0.05), 4,10 \%$ of miscarriage rate vs $6,8 \%$ in no-ART group $(\mathrm{p}<0.05)$, and bith rate of $100 \%$ vs $83 \%$ in no-ART group $(\mathrm{p}<0.01)$. Concerning ovarian hormonal function, an $\mathrm{FSH}$ value $>40 \mathrm{mUI} / \mathrm{ml}$ was found in only one patient $(6,25 \%)$ and an estradiol values $<20 \mathrm{pg} / \mathrm{ml}$ in a percentage of $18,5 \%$. Turning to $\mathrm{AMH}$ value: all patients had AMH above $0,1 \mathrm{ng} /$ $\mathrm{ml}, 3$ patients $(18,75 \%)$ had $\mathrm{AMH}$ between 0.1 and $1 \mathrm{ng} / \mathrm{ml}$, $13(81,25)$ patients had AMH values $>1 \mathrm{ng} / \mathrm{ml}$.

Conclusion Our study represents an analysis of the globally fertility in patients with OC. Pregnancy and fertility results following ART seems to be promising, though the reproductive outcome are significantly better when patients are sent to ART.

Disclosures The authors have no conflicts of interest to declare. 